\title{
AN INVESTIGATION INTO ASSESSMENT CRITERIA OF THE CONTENT CONTEXT AND FORMS OF EXTRACURRICULAR SPORTS ACTIVITIES FOR STUDENTS AT SECONDARY SCHOOLS IN TAY NINH PROVINCE, VIETNAM
}

\author{
Nguyen Thanh Tuan ${ }^{1 \mathrm{i}}$, \\ Duong Ngoc Truong', \\ Nguyen Quang Son ${ }^{3}$ \\ ${ }^{1}$ Secondary School, \\ Tay Ninh Province, \\ Vietnam \\ ${ }^{2} \mathrm{PhD}$, Saigon University, \\ Vietnam \\ ${ }^{3}$ University of Economics Ho Chi Minh City, \\ Vietnam
}

\begin{abstract}
:
After using the conventional scientific research methods, observing the steps of document synthesis, interviewing, and checking the reliability of the questionnaire through Cronbach's Alpha, the paper has come up with five quantitative assessment criteria and eight qualitative assessment questions of the content and forms of extracurricular sports activities for students at secondary schools in Tay Ninh province. This research has contributed to renewing the content and forms of extracurricular sports activities for students at secondary school.
\end{abstract}

Keywords: criteria, content context, forms of organization, extracurricular sports, students at secondary school, Tay Ninh province

\section{Introduction}

Extracurricular sports activities are voluntary organized sports activities conducting outside of regular school hours suitable for hobbies, gender, age, and health of students. Extracurricular sports activities are diversified, consists of the sports activities were regulated during recess, team training, training in sports clubs, and competitive sports activities. The content of extracurricular sports activities is so extremely plentiful that it goes beyond the content specified in the mainstream physical education curriculum

i Correspondence: sonnq@ueh.edu.vn 
without restricted by the program. Extracurricular sports activities not only can be conducted in the school, but also, they can be held outside the school, so the activity space compared to the physical education curriculum is quite much larger. The forms of extracurricular sports activities are quite diversified and the method is flexible, which can be conducted in many different forms namely, the whole school, the whole course, the whole class or groups, and individual context, so this method can satisfy the different requirements of students. The operation of time is also not as strict as the regular physical education class which can be conducted at any time, if it is suitable condition for permission of students.

In the past years, with the attention from the Department of Education and Training, the Education Department, the School of Directors Board, extracurricular sports activities at secondary schools in Tay Ninh province have achieved many positive results. However, to ensure extracurricular sports activities are more effective than in the coming time, so it is necessary to build scientific bases for suitable to the context with the conditions of facilities, staff, and the resources of the school. To have a base for enhancing extracurricular sports activities for students need to assess accurately and comprehensively the context of this activity. Therefore, it plays an important role in developing criteria to assess them. Coming from these problems mentioned above, the authors select the subject: "An investigation into assessment criteria of the content context and forms of extracurricular sports activities for students at secondary schools in Tay Ninh province, Vietnam".

The purpose of the study is to select criteria to assess the content context and forms of organizational extracurricular sports activities for students at secondary schools in Tay Ninh province in a comprehensive, scientific, and accurate manner.

Research methods: the method of document synthesis and analysis, interview method, and statistical method.

\subsection{Participants}

At the study participated 200 students from Chu Van An at Secondary School in Tay Ninh City; 5 people are experts, Managers of Physical Education of the Department of Education and Training and experts of Physical Education in Tay Ninh province, Ho Chi Minh City University of Physical Education and Sports.

\section{Research results}

To assess the content context and forms of organizational extracurricular sports activities for students at secondary schools in Tay Ninh province need to have an accurate, scientific and comprehensive assessment criterion. The paper conducted identify assessment criteria of two categories including: Quantitative assessment criteria and qualitative assessment criteria. 


\subsection{Quantitative assessment criteria}

The research proceeds in 2 steps following as:

Step 1: To synthesize assessment criteria for assessing the content and forms of extracurricular sports activities from research works of home and abroad authors.

To synthesize assessment criteria for assessing the content and forms of extracurricular sports activities of the authors namely, Tran Thi Xoan (2006) [12], Tran Kim Cuong (2008) [6], Nguyen Duc Thanh (2013) [10], Author Tran Huu Hung (2015) [8], Phung Xuan Dung (2017) [7], Dang Minh Thanh (2018) [11], Law on Sports and Sports (2018) [9], Circular No. 02/2009/TT-BVHTTDL (2009) [3], Circular No. 08/2012/TTBVHTTDL (2012) [4], Circular No: 01/2019/TT-BVHTTDL (2019) [5].

In consultation of experts, based on my own reality and experience, the researchers opted for quantitative assessment criteria including the criteria following as: Criterion 1: Percentage of students achieving physical standards according to the decision No. 53/2008/BGDĐT of the Ministry of Education and Training or the school's standards.

- Criterion 2: Percentage of students participating in extracurricular exercises;

- Criterion 3: Percentage of students participating in sports tournaments organized by the school;

- Criterion 4: The number of sports teams and extracurricular sport clubs;

- Criterion 5: The number of sports teams representing the school participating in the competition.

Step 2: Interviews with experts

To conduct questionnaire development and interview with five people who are experts, Managers of Physical Education of the Department of Education and Training and the experts of Physical Education in Tay Ninh province, Ho Chi Minh City University of Physical Education and Sport, using a five-point Likert- scale, ranging from 1 to 5 (1: Strongly disagree, 2: Disagree, 3: Neutral, 4: Agree, 5: Strongly agree); the results are presented in Table 1.

Table 1: Results of interviews with quantitative assessment criteria of content context and forms of organizational extracurricular sports activities for students at secondary schools in Tay Ninh province $(n=5)$

\begin{tabular}{|l|l|c|c|}
\hline \multirow{2}{*}{ No } & Criteria & \multicolumn{2}{|c|}{ Results of interviews } \\
\cline { 2 - 3 } 2 & $\begin{array}{l}\text { Percentage of students achieving physical standards according to the } \\
\text { decision No. 53/2008/BGDĐT of the Ministry of Education and } \\
\text { Training or the school's standards. }\end{array}$ & $\begin{array}{c}\text { Percentage } \\
\mathbf{( \% )}\end{array}$ \\
\hline 2 & Percentage of students participating in extracurricular exercises. & 25 & 100.0 \\
\hline 3 & $\begin{array}{l}\text { Percentage of students participating in competitions organized by the } \\
\text { school. }\end{array}$ & 21 & 86.0 \\
\hline 4 & The number of sports teams and extracurricular sport clubs. & 22 & 88.0 \\
\hline
\end{tabular}


The results of the interview as can be seen in Table 1, all of criteria were selected by experts stood at over $80 \%$. As a result, five criteria were selected for quantitative assessment of the content context and forms of organizational extracurricular sports activities for students at secondary schools in Tay Ninh Province:

- Criterion 1: Percentage of students achieving physical standards according to the decision No. 53/2008/BGDĐT of the Ministry of Education and Training or the school's standards. Method of assessment: Percentage of students achieving physical standards according to the decision No. 53/2008/BGDĐT of the Ministry of Education and Training or the school's standards out of the total number of students in the whole school.

- Criterion 2: Percentage of students participating in extracurricular exercises. Method of assessment: Percentage of students participating in extracurricular exercises over the total number of students in the whole school.

- Criterion 3: Percentage of students participating in competitions organized by the school. Method of assessment: Percentage of students participating in competitions organized by the school out of the total number of students in the whole school.

- Criterion 4: The number of sports teams and extracurricular sport clubs. Method of assessment: Total number of sports teams and extracurricular sport clubs in the school.

- Criterion 5: The number of sports teams representing the school participating in the competition. Method of assessment: Total number of sports teams representing the school participating in the competition.

\subsection{Qualitative assessment criteria}

The research conducts a qualitative assessment of the content context and forms of organizational extracurricular sports activities for students at secondary schools in Tay Ninh province through a questionnaire.

As can be seen in quantitative research, the researchers use different accurate measurement scales and highly reliable. In the field of research in Educational Psychology - Sociology (qualitative research) as the paper is, the level of criteria is very complicated, which requires a scale to be measured meticulously and to check the degree of accuracy trust before using.

To check the reliability of the scale above, the research conducts 3 steps following as:

Step 1: To draft the initial preliminary questionnaire.

The paper has preliminarily constructed the initial questionnaire (Appendix 1). After, consulting five people who are experts, Managers of Physical Education of the 
Department of Education and Training and the experts of Physical Education in Tay Ninh province, Ho Chi Minh City University of Physical Education and Sport with review the structure, form, content, and purpose of the interview form to contribute and supplement ideas for testing the scale of reality of the survey result criteria following as:

- $3 / 5$ experts accounted for $60 \%$ agree on the questionnaire form.

- $2 / 5$ experts stood at $40 \%$ suggested removing 1 question item and adjusting the sentences and words in 2 questions.

Step 2: To adjust the questionnaire of the scale and determine the answer form.

Through the survey results and additional opinions of experts, the researchers adjusted the questions suitable for (Appendix 2) and carried out data collection to process by the SPSS software, version 22 (Statistic Package for the Social Sciences). The content of the form of the questionnaire of the scale and forms of organizational extracurricular sports activities for students at secondary schools in Tay Ninh province consists of 9 questions. To determine the form of responses, in this paper, was considered the answer form a fivepoint Likert- scale to conduct a survey on 200 students at Secondary Schools in Tay Ninh City. The students are selected survey with ranging from 1 to 5 with contents related to the content context and forms of organizational extracurricular sports activities for students at secondary schools in Tay Ninh Province.

Step 3: To check the reliability of the questionnaire using Cronbach's Alpha.

To assess accurately the reliability of the survey, the researchers conducted assess the scale using Cronbach's Alpha reliability coefficient. The scale to assess the content and forms of organizational extracurricular sports activities for students at secondary schools in Tay Ninh province including (9 criteria).

\section{a. Content}

- Criterion 1: Suitable for students' needs and interests,

- Criterion 2: Suitable for school yards and equipment,

- Criterion 3: Consistent with the professional qualifications of the team of teachers and coaches,

- Criterion 4: To effect of developing physical strength for students,

- Criterion 5: To effect of developing sports talent for students.

\section{b. Form of organization}

- Criterion 6: Flexible and varied training time,

- Criterion 7: Flexible and diverse practice locations and times,

- Criterion 8: Diversity, forms of extracurricular sports (teams, sports clubs, sports teams ...),

- Criterion 9: Suitable for students' financial ability. 
The results of testing the scale to assess the content and forms of organizational extracurricular sports activities for students at secondary schools in Tay Ninh province by Cronbach's Alpha are shown in Table 2.

Table 2: Description of the Cronbach's Alpha reliability coefficient of the scale of questionnaire items to assess the content and forms of organizational extracurricular sports activities for students at secondary schools in Tay Ninh province

\begin{tabular}{|l|c|c|c|c|}
\hline Questions & $\begin{array}{c}\text { Scale Mean if } \\
\text { Item Deleted }\end{array}$ & $\begin{array}{c}\text { Scale Variance if } \\
\text { Item Deleted }\end{array}$ & $\begin{array}{c}\text { Corrected Item- } \\
\text { Total Correlation }\end{array}$ & $\begin{array}{c}\text { Cronbach's Alpha if } \\
\text { Item Deleted }\end{array}$ \\
\hline Cr 1 & 31.60 & 8.833 & .454 & .778 \\
\hline Cr 2 & 31.92 & 8.657 & .500 & .772 \\
\hline Cr 3 & 31.67 & 8.624 & .448 & .779 \\
\hline Cr 4 & 32.25 & 8.578 & .478 & .775 \\
\hline Cr 5 & 32.54 & 8.451 & .522 & .769 \\
\hline Cr 6 & 31.86 & 8.463 & .549 & .765 \\
\hline Cr 7 & 32.20 & 8.864 & .461 & .777 \\
\hline Cr 8 & 32.52 & 8.693 & .510 & .771 \\
\hline Cr 9 & 32.40 & 9.025 & .270 & .782 \\
\hline Cronbach's Alpha $=.794$ & & \\
\hline N of Items = 9
\end{tabular}

The results of Cronbach's Alpha test of the scales are shown in Table 3, Cronbach's Alpha coefficient total $=0.794>0.6$, there are 8 items with correlation coefficient with the total variable. (Corrected Item-Total Correlation) was greater than the allowed standard $(>0.3)$ and 1 question is suitable for students' financial ability ( $\mathrm{Cr} 9$ ) with total variable correlation coefficient $<0.3$, so this question should be removed.

The paper examines the scale to assess the content and forms of organizational extracurricular sports activities for students at secondary schools in Tay Ninh province using Cronbach's Alpha for eight outcome criteria are presented in Table 3.

Table 3: Description of the Cronbach's Alpha reliability coefficient of the scale of the questionnaire items to assess the content and forms of organizational extracurricular sports activities for students at secondary schools in Tay Ninh province (2nd time)

\begin{tabular}{|l|c|c|c|c|}
\hline Questions & $\begin{array}{c}\text { Scale Mean if } \\
\text { Item Deleted }\end{array}$ & $\begin{array}{c}\text { Scale Variance if } \\
\text { Item Deleted }\end{array}$ & $\begin{array}{c}\text { Corrected Item- } \\
\text { Total Correlation }\end{array}$ & $\begin{array}{c}\text { Cronbach's Alpha if } \\
\text { Item Deleted }\end{array}$ \\
\hline Cr 1 & 27.88 & 7.228 & .474 & .254 \\
\hline Cr 2 & 28.20 & 7.035 & .532 & .358 \\
\hline Cr 3 & 27.95 & 7.083 & .450 & .254 \\
\hline Cr 4 & 28.53 & 6.934 & .516 & .414 \\
\hline Cr 5 & 28.82 & 6.882 & .540 & .415 \\
\hline Cr 6 & 28.14 & 7.036 & .518 & .413 \\
\hline Cr 7 & 28.48 & 7.427 & .419 & .313 \\
\hline Cr 8 & 28.80 & 7.377 & .431 & .310 \\
\hline Cronbach's Alpha $=.782$ & & \\
\hline N of Items $=8$ &
\end{tabular}


The results of Cronbach's Alpha test of the scales are presented in Table 3.

Cronbach's Alpha coefficient total $=0.782>0.6$, all items have a correlation coefficient with the total variable. (Corrected Item-Total Correlation) was greater than the allowed standard $(>0.3)$. The paper has built a scale to assess the content and forms of organizational extracurricular sports activities for students at secondary schools in Tay Ninh province with eight questions:

\section{a. Content}

- Criterion 1: Suitable for students' needs and interests,

- Criterion 2: Suitable for school yards and equipment,

- Criterion 3: Consistent with the professional qualifications of teachers and coaches,

- Criterion 4: To effect of developing physical strength for students,

- Criterion 5: To effect of developing sports talent for students.

\section{b. Form}

- Criterion 6: Flexible and varied training time,

- Criterion 7: Flexible and diverse practice locations and times,

- Criterion 8: Diversity, forms of extracurricular sports (teams, sports clubs, national teams).

\section{Conclusion}

By synthesizing related literature, the results of questionnaires delivered to experts, management staff, lecturers and students and the analysis of Cronbach's Alpha, the study has selected five quantitative criteria and eight qualitative criteria which are able to employ for assessment the content and forms of extracurricular sports activities for students at secondary schools in Tay Ninh province.

\section{Conflict of Interest Statement}

The authors declare no conflicts of interests.

\section{About the Authors}

Nguyen Thanh Tuan has been a P.E teacher at a lower secondary school in Tay Ninh province, Vietnam. At the same time, he is attending $\mathrm{PhD}$ program at Ho Chi Minh University of Physical Education and Sports, Vietnam.

Duong Ngoc Truong has held his PhD degree and has been working at Sai Gon University, Vietnam.

Nguyen Quang Son has held his PhD degree and has been working at University of Economics Ho Chi Minh City. Vietnam. 


\section{References}

[1]. Ministry of Education and Training (2008), Decision No. 53/2008/QD-BGDĐT on $19 / 8 / 2008$, on the issue of regulations of the assessment and classification of students' physical fitness.

[2]. Ministry of Education and Training (2008), Decision No. 72/2008/QD-BGDDT on $23 / 12 / 2008$, on promulgating regulations of organization of extracurricular sports activities for students.

[3]. Ministry of Culture, Sports and Tourism (2009), Circular No. 02/2009/TT-BVHTTDL, dated March 17, 2009, V/v: Guiding the organization and assessment of mass sports and sports movements. In section II. Assess the local mass sport movement.

[4]. Ministry of Culture, Sports and Tourism (2012), Circular No. 08/2012/TT-BVHTTDL, dated September 10, 2012 of the Minister of Culture, Information and Tourism; $\mathrm{V} / \mathrm{v}$ : Regulation on assessment content of physical training and sports development.

[5]. Ministry of Culture, Sports and Tourism (2019), Circular No. 01/2019/TT-BVHTTDL, dated January 17, 2019, V/v: Regulations on assessment of mass sports and sports movements.

[6]. Tran Kim Cuong (2008), The reality of extracurricular sports practice in schools in Ninh Binh province, Journal of Sports Science (6), Institute of Sports Science, Hanoi, pp.56- 60 .

[7]. Phung Xuan Dung (2017), Research on solutions to improve the effectiveness of extracurricular sports activities for students of Hanoi University of Sports and Physical Education, PhD thesis in Education, Institute of Sports Science.

[8]. Tran Huu Hung (2015), Research on improving the form and content of physical training exercises for junior high school students in the Gia Lai - Kon Tum highland area, $\mathrm{PhD}$ thesis in Education, Institute of Sports Science.

[9]. National Assembly of the Socialist Republic of Vietnam (2018), Amendment and supplementation of a number of articles of the Law on Physical Training and Sports, Law No. 26/2018/QH14, dated June 14, 2018.

[10]. Nguyen Duc Thanh (2013), Developing content and form of organizing extracurricular sports activities of students of some universities in Ho Chi Minh City, PhD thesis in Education, Institute of Sports Science.

[11]. Dang Minh Thanh (2018), Innovating the content and methods of organizing extracurricular sports activities for students in Soc Trang province, Doctoral thesis in Education, Institute of Sports Science.

[12]. Tran Thi Xoan (2006), Research and development of extracurricular sports suitable for women, Master thesis, University of Sports and Sports II.

[13]. Hoang Trong, Chu Nguyen Mong Ngoc (2008), Analyzing research data with SPSS, Hong Duc Publishing House. 
Nguyen Thanh Tuan, Duong Ngoc Truong, Nguyen Quang Son

AN INVESTIGATION INTO ASSESSMENT CRITERIA OF THE CONTENT CONTEXT

AND FORMS OF EXTRACURRICULAR SPORTS ACTIVITIES FOR STUDENTS

AT SECONDARY SCHOOLS IN TAY NINH PROVINCE, VIETNAM

Creative Commons licensing terms

Authors will retain the copyright of their published articles agreeing that a Creative Commons Attribution 4.0 International License (CC BY 4.0) terms will be applied to their work. Under the terms of this license, no permission is required from the author(s) or publisher for members of the community to copy, distribute, transmit or adapt the article content, providing a proper, prominent and unambiguous attribution to the authors in a manner that makes clear that the materials are being reused under permission of a Creative Commons License. Views, opinions and conclusions expressed in this research article are views, opinions and conclusions of the author(s). Open Access Publishing Group and European Journal of Physical Education and Sport Science shall not be responsible or answerable for any loss, damage or liability caused in relation to/arising out of conflict of interests, copyright violations and inappropriate or inaccurate use of any kind content related or integrated on the research work. All the published works are meeting the Open Access Publishing requirements and can be freely accessed, shared, modified, distributed and used in educational, commercial and non-commercial purposes under a Creative Commons attribution 4.0 International License (CC BY 4.0). 